\title{
On the geometric concomitant equation
}

\section{ZENON MOSZneR}

Dedicated to Professor János Aczél on 95th anniversary of his birth.

\begin{abstract}
We solve in some cases the equation in the definition of the concomitant of a geometric object for each of the four functions in this equation. Remarks and examples are given, too.
\end{abstract}

Mathematics Subject Classification. 39B52.

Keywords. Equation of geometric concomitant, Associated equation, Translation equation.

\section{Introduction}

For $\mathrm{i}=1,2$ let $\mathrm{S}_{\mathrm{i}}$ be a set and let $\left(\mathrm{G}_{\mathrm{i}},+\right)$ be a groupoid. Let the function $F_{i}: S_{i} \times G_{i} \rightarrow S_{i}$ be the solution of the translation equation, i.e., such that

$$
\mathrm{F}_{\mathrm{i}}\left(\mathrm{F}_{\mathrm{i}}\left(\mathrm{x}, \mathrm{t}_{1}\right), \mathrm{t}_{2}\right)=\mathrm{F}_{\mathrm{i}}\left(\mathrm{x}, \mathrm{t}_{1}+\mathrm{t}_{2}\right) \text { for } \mathrm{x} \in \mathrm{S}_{\mathrm{i}}, \mathrm{t}_{1}, \mathrm{t}_{2} \in \mathrm{G}_{\mathrm{i}} \quad \text { for } \mathrm{i}=1,2 \text {. }
$$

The equation

$$
\mathrm{f}\left[\mathrm{F}_{1}(\mathrm{x}, \mathrm{t})\right]=\mathrm{F}_{2}[\mathrm{f}(\mathrm{x}), \mathrm{h}(\mathrm{t})] \quad \text { for }(\mathrm{x}, \mathrm{t}) \in \mathrm{S}_{1} \times \mathrm{G}_{1},
$$

where $f: S_{1} \rightarrow S_{2}$ and $h$ is a homomorphism from $G_{1}$ to $G_{2}$, is said to be the geometric concomitant equation.

This equation means that the diagram

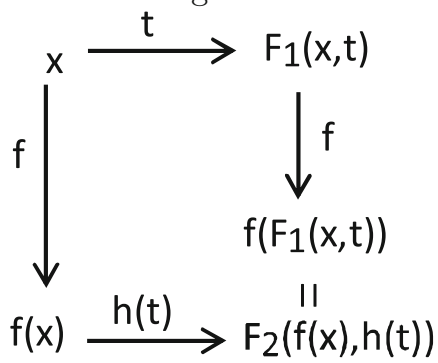

is commutative. 
If $\mathrm{G}_{1}=\mathrm{G}_{2}, \mathrm{~h}(\mathrm{t})=\mathrm{t}$ for $\mathrm{t} \epsilon \mathrm{G}_{1}, \mathrm{G}_{1}$ has the neutral element 0 and $\mathrm{F}_{\mathrm{i}}(\mathrm{x}, 0)=\mathrm{x}$ for $x \in S_{i}, i=1,2$, then in the theory of geometric objects [1] the function $F_{1}$ is the transformation law of the object $\mathrm{x}, \mathrm{f}(\mathrm{x})$ is the concomitant of this object $\mathrm{x}[4]$ and $\mathrm{F}_{2}$ is the transformation law of the object $\mathrm{f}(\mathrm{x})$.

If $\mathrm{f}$ is a bijection, then $\mathrm{F}_{1}$ and $\mathrm{F}_{2}$ are said to be equivalent (e.g., in the theory of abstract automata [11]).

If $\mathrm{G}$ is a group, then $\mathrm{G} / \mathrm{G}^{*}$ means the family of the right cosets of the group $\mathrm{G}$ for the subgroup $\mathrm{G}^{*}$ throughout the paper.

We have four functions in Eq. (1), thus there are four possibilities for the unknown function.

\section{Unknown function $f$}

Let $\mathrm{G}_{\mathrm{i}}$ be a group and let $\mathrm{F}_{\mathrm{i}}(\mathrm{x}, 0)=\mathrm{x}$ for $\mathrm{x} \in \mathrm{S}_{\mathrm{i}}$ and $\mathrm{i}=1,2$. The solution $\mathrm{F}_{\mathrm{i}}$ of the translation equation has the form

$$
\mathrm{F}_{\mathrm{i}}(\mathrm{x}, \mathrm{t})=\mathrm{b}_{\mathrm{i}}^{-1}\left[\mathrm{~b}_{\mathrm{i}}(\mathrm{x})+\mathrm{t}\right] \quad \text { for }(\mathrm{x}, \mathrm{t}) \in \mathrm{S}_{\mathrm{i}} \times \mathrm{G}_{\mathrm{i}},
$$

where $\mathrm{b}_{\mathrm{i}}=\cup_{\mathrm{k} \in K_{i}}: \mathrm{b}_{\mathrm{ik}}, \mathrm{S}_{\mathrm{i}}=\cup_{\mathrm{k} \in K_{i}}: \mathrm{S}_{\mathrm{ik}}, \mathrm{S}_{\mathrm{ik}}$ for $\mathrm{k} \in \mathrm{K}_{\mathrm{i}}$ are non-empty disjoint sets such that for every $k \in K_{i}$ there exists a subgroup $G_{i k}$ of the group $G_{i}$ for which card $_{\mathrm{ik}}=\operatorname{card}_{\mathrm{i}} / \mathrm{G}_{\mathrm{ik}}$ and $\mathrm{b}_{\mathrm{ik}}: \mathrm{S}_{\mathrm{ik}} \rightarrow \mathrm{G}_{\mathrm{i}} / \mathrm{G}_{\mathrm{ik}}$ is a bijection $([5,7])$.

From here the above function $F_{i}$ and the solution of the translation equation $F_{i}(\mathrm{u}, \mathrm{t})=\mathrm{u}+\mathrm{t}:\left(\cup_{\mathrm{k} \in K_{i}} \mathrm{G}_{\mathrm{i}} / \mathrm{G}_{\mathrm{ik}}\right) \times \mathrm{G}_{\mathrm{i}} \rightarrow \cup_{\mathrm{k} \in K_{i}} \mathrm{G}_{\mathrm{i}} / \mathrm{G}_{\mathrm{ik}}$ are equivalent since $\mathrm{b}_{\mathrm{i}}\left(\mathrm{F}_{\mathrm{i}}(\mathrm{x}, \mathrm{t})\right)=\mathrm{b}_{\mathrm{i}}(\mathrm{x})+\mathrm{t}=F_{i}\left(\mathrm{~b}_{\mathrm{i}}(\mathrm{x}), \mathrm{t}\right)$. This implies that the solution $\mathrm{F}: \mathrm{S} \times \mathrm{G} \rightarrow$ $\mathrm{S}$ such that $\mathrm{G}$ is a group and $\mathrm{F}(\mathrm{s}, 0)=\mathrm{s}$ for $\mathrm{s} \in \mathrm{S}$ may be identified with the family of the right cosets of the group $\mathrm{G}$.

Theorem 1. If $F_{\mathrm{i}}$ are of the form (2), then a function $f: S_{1} \rightarrow S_{2}$ is a solution of (1) if and only if there exist functions $\alpha: K_{1} \rightarrow G_{2}$ and $\beta: K_{1} \rightarrow K_{2}$ such that

$$
h\left(G_{1 \mathrm{k}}\right) \subset\left[-\alpha(k)+G_{2 \beta(\mathrm{k})}+\alpha(k)\right] \text { for } k \in K_{1}
$$

and $f$ is of the form $f=b_{2}^{-1} \varphi b_{1}$, where

$\varphi(C)=\varphi\left(G_{1 \mathrm{k}}+t\right)=G_{2 \beta(\mathrm{k})}+\alpha(k)+h(t)$ for $C=G_{1 \mathrm{k}}+t \in G_{1} / G_{1 \mathrm{k}}$ and $k \in K_{1}$.

Proof. Note that the function $\varphi$ defined in (4) is well-defined. In fact, if $\mathrm{G}_{1 \mathrm{k}}+$ $\mathrm{t}_{1}=\mathrm{G}_{1 \mathrm{k}}+\mathrm{t}_{2}$, then $\mathrm{t}_{2}-\mathrm{t}_{1} \in \mathrm{G}_{1 \mathrm{k}}$, thus the function

$$
\mathrm{h}\left(\mathrm{t}_{2}-\mathrm{t}_{1}\right) \epsilon\left[-\alpha(\mathrm{k})+\mathrm{G}_{2 \beta(\mathrm{k})}+\alpha(\mathrm{k})\right]=: \mathrm{A} .
$$

Since $A$ is a group, $A+h\left(t_{2}-t_{1}\right)=A$. This yields that $A+h\left(t_{2}\right)=A+h\left(t_{1}\right)$.

Let $\mathrm{f}$ be a solution of (1). Then the function $\varphi=\mathrm{b}_{2} \mathrm{fb}_{1}^{-1}$ is a solution of the equation

$$
\varphi(\mathrm{C}+\mathrm{t})=\varphi(\mathrm{C})+\mathrm{h}(\mathrm{t})
$$


where $\varphi: \cup_{\mathrm{k} \in K_{1}}: \mathrm{G}_{1} / \mathrm{G}_{1 \mathrm{k}} \rightarrow \cup_{\mathrm{k} \in K_{2}}: \mathrm{G}_{2} / \mathrm{G}_{2 \mathrm{k}}$. Indeed, for $\mathrm{C} \epsilon \cup_{\mathrm{k} \in K_{1}}: \mathrm{G}_{1} / \mathrm{G}_{1 \mathrm{k}}$ there exists $\mathrm{x} \in \mathrm{S}_{1}$ such that $\mathrm{b}_{1}(\mathrm{x})=\mathrm{C}$ thus $\mathrm{x}=\mathrm{b}_{1}^{-1}(\mathrm{C})$ and

$$
\begin{aligned}
\mathrm{b}_{2} \mathrm{fb}_{1}^{-1}(\mathrm{C}+\mathrm{t}) & =\mathrm{b}_{2} \mathrm{fb}_{1}^{-1}\left(\mathrm{~b}_{1}(\mathrm{x})+\mathrm{t}\right)=\mathrm{b}_{2} \mathrm{f}\left(\mathrm{F}_{1}(\mathrm{x}, \mathrm{t})\right)=\mathrm{b}_{2} \mathrm{~F}_{2}(\mathrm{f}(\mathrm{x}), \mathrm{h}(\mathrm{t})) \\
& =\mathrm{b}_{2} \mathrm{~b}_{2}^{-1}\left[\mathrm{~b}_{2}(\mathrm{f}(\mathrm{x}))+\mathrm{h}(\mathrm{t})\right]=\mathrm{b}_{2} \mathrm{fb}_{1}^{-1}(\mathrm{C})+\mathrm{h}(\mathrm{t}) .
\end{aligned}
$$

Since $\varphi\left(\mathrm{G}_{1 \mathrm{k}}\right) \epsilon \cup_{\mathrm{k} \in K_{2}}: \mathrm{G}_{2} / \mathrm{G}_{2 \mathrm{k}}$ there exist functions $\alpha: \mathrm{K}_{1} \rightarrow \mathrm{G}_{2}$ and $\beta$ : $\mathrm{K}_{1} \rightarrow \mathrm{K}_{2}$ such that $\varphi\left(\mathrm{G}_{1 \mathrm{k}}\right)=\mathrm{G}_{2 \beta(\mathrm{k})}+\alpha(\mathrm{k})$. We have thus for $t \in \mathrm{G}_{1 \mathrm{k}}$ that $\varphi\left(\mathrm{G}_{1 \mathrm{k}}+\mathrm{t}\right)=\varphi\left(\mathrm{G}_{1 \mathrm{k}}\right)=\varphi\left(\mathrm{G}_{1 \mathrm{k}}\right)+\mathrm{h}(\mathrm{t})$. This yields that $\mathrm{G}_{2 \beta(\mathrm{k})}+\alpha(\mathrm{k})=\mathrm{G}_{2 \beta(\mathrm{k})}+$ $\alpha(\mathrm{k})+\mathrm{h}(\mathrm{t})$. From here $\mathrm{h}(\mathrm{t}) \epsilon\left[-\alpha(\mathrm{k})+\mathrm{G}_{2 \beta(\mathrm{k})}+\alpha(\mathrm{k})\right]$ if $\mathrm{t} \epsilon \mathrm{G}_{1 \mathrm{k}}$. This implies $\mathrm{h}\left(\mathrm{G}_{1 \mathrm{k}}\right) \subset\left[-\alpha(\mathrm{k})+\mathrm{G}_{2 \beta(\mathrm{k})}+\alpha(\mathrm{k})\right]$. Moreover for $\mathrm{C}=\mathrm{G}_{1 \mathrm{k}}+\mathrm{t}$ we obtain

$$
\varphi(\mathrm{C})=\varphi\left(\mathrm{G}_{1 \mathrm{k}}+\mathrm{t}\right)=\varphi\left(\mathrm{G}_{1 \mathrm{k}}\right)+\mathrm{h}(\mathrm{t})=\mathrm{G}_{2 \beta(\mathrm{k})}+\alpha(\mathrm{k})+\mathrm{h}(\mathrm{t}) .
$$

Assume now that $\mathrm{f}=\mathrm{b}_{2}^{-1} \varphi \mathrm{b}_{1}$ with $\varphi$ as in (4). The function $\varphi$ is a solution of the Eq. (5) since for $\mathrm{C}=\mathrm{G}_{1 \mathrm{k}}+\mathrm{t}_{1}$

$$
\begin{aligned}
\varphi(\mathrm{C}+\mathrm{t}) & =\varphi\left(\mathrm{G}_{1 \mathrm{k}}+\mathrm{t}_{1}+\mathrm{t}\right)=\mathrm{G}_{2 \beta(\mathrm{k})}+\alpha(\mathrm{k})+\mathrm{h}\left(\mathrm{t}_{1}+\mathrm{t}\right) \\
& =\mathrm{G}_{2 \beta(\mathrm{k})}+\alpha(\mathrm{k})+\mathrm{h}\left(\mathrm{t}_{1}\right)+\mathrm{h}(\mathrm{t})=\varphi\left(\mathrm{G}_{1 \mathrm{k}}+\mathrm{t}_{1}\right)+\mathrm{h}(\mathrm{t})=\varphi(\mathrm{C})+\mathrm{h}(\mathrm{t}) .
\end{aligned}
$$

From here we have

$$
\begin{aligned}
f\left[F_{1}(x, t)\right] & =b_{2}^{-1} \varphi b_{1}\left[b_{1}^{-1}\left(b_{1}(x)+t\right)\right]=b_{2}^{-1} \varphi\left(b_{1}(x)+t\right)=b_{2}^{-1}\left[\varphi\left(b_{1}(x)\right)+h(t)\right] \\
& =b_{2}^{-1}\left[b_{2} b_{2}^{-1} \varphi\left(b_{1}(x)\right)+h(t)\right]=b_{2}^{-1}\left[b_{2}(f(x))+h(t)\right]=F_{2}(f(x), h(t)) .
\end{aligned}
$$

Remark. The solution $\mathrm{f}$ of (1) is a function from $\mathrm{S}_{1}$ to $\mathrm{S}_{2}$ but only the stability groups $\mathrm{G}_{\mathrm{ik}}$ and the homomorphism $\mathrm{h}$ decide about the existence of this solution.

Examples. 1. Put

$$
\begin{aligned}
& \mathrm{F}_{1}(\mathrm{x}, \mathrm{t})=\mathrm{tn}^{-1}(\operatorname{tn} \mathrm{x}+\mathrm{t}) \text { for } \mathrm{x} \in\left(-\frac{\pi}{2}, \frac{\pi}{2}\right), \mathrm{t} \in \mathbb{R}, \\
& \mathrm{F}_{2}(\mathrm{x}, \mathrm{t})= \begin{cases}\exp (\ln \mathrm{x}+\mathrm{t}) & \text { for } \mathrm{x}>0, \mathrm{t} \in \mathbb{R}, \\
0 & \text { for } \mathrm{x}=0, \mathrm{t} \in \mathbb{R}, \\
-\exp (\ln (-\mathrm{x})+\mathrm{t}) & \text { for } \mathrm{x}<0, \mathrm{t} \in \mathbb{R}\end{cases}
\end{aligned}
$$

and $\mathrm{h}(\mathrm{t})=\mathrm{t}$.

We have $\mathrm{G}_{1}=\mathrm{G}_{2}=\mathbb{R}, \mathrm{S}_{1}=\left(-\frac{\pi}{2}, \frac{\pi}{2}\right), \mathrm{K}_{1}=\{1\}, \mathrm{S}_{11}=\mathrm{S}_{1}, \mathrm{~b}_{11}=\mathrm{tn}$, $\mathrm{G}_{11}=\{0\}, \mathrm{S}_{2}=\mathbb{R}, \mathrm{K}_{2}=\{1,2,3\}, \mathrm{S}_{21}=(0,+\infty), \mathrm{S}_{22}=\{0\}, \mathrm{S}_{23}=(-\infty, 0)$, $\mathrm{b}_{21}=\ln , \mathrm{b}_{22}=0, \mathrm{~b}_{23}(\mathrm{x})=\ln (-\mathrm{x}), \mathrm{G}_{21}=\{0\}, \mathrm{G}_{22}=\mathbb{R}, \mathrm{G}_{23}=\{0\}$.

The condition (3) has the form $\mathrm{G}_{11} \subset \mathrm{G}_{2 \mathrm{~b}(1)}$ and this is true for $\beta(1)=$ $1,2,3$ and for every $\alpha(1)=: a \in \mathbb{R}$.

If $\beta(1)=1$, then $\varphi\left(\mathrm{G}_{11}+\mathrm{t}\right)=\varphi(\{0\}+\mathrm{t})=\{0\}+\mathrm{a}+\mathrm{t}$. For $\mathrm{C}(\mathrm{t}):=\{0\}+\mathrm{t}$ we have $\varphi(\mathrm{C}(\mathrm{t}))=\mathrm{C}(\mathrm{a}+\mathrm{t})$. From here $\varphi\left(\mathrm{b}_{11}(\mathrm{x})\right)=\varphi(\mathrm{C}(\operatorname{tnx}))=\mathrm{C}(\mathrm{a}+\mathrm{tnx})$. This yields that

$$
f(x)=b_{21}^{-1}(C(a+\operatorname{tn} x))=\exp (a+\operatorname{tn} x)
$$



$\operatorname{tnx})$.

Analogously if $\beta(1)=2$, then $\mathrm{f}(\mathrm{x})=0$ and if $\beta(1)=3$, then $\mathrm{f}(\mathrm{x})=-\exp (\mathrm{a}+$

From here the functions $\mathrm{f}(\mathrm{x})=\varepsilon \exp (\mathrm{a}+\operatorname{tnx})$ for $\mathrm{x} \in\left(-\frac{\pi}{2}, \frac{\pi}{2}\right), \mathrm{a} \in \mathbb{R}, \varepsilon \in\{-1,0,1\}$ are the only solutions of (1) in the case of the above functions $F_{1}$ and $F_{2}$.

2. The equation

$$
\mathrm{f}\left[\mathrm{F}_{2}(\mathrm{x}, \mathrm{t})\right]=\mathrm{F}_{1}(\mathrm{f}(\mathrm{x}), \mathrm{h}(\mathrm{t})),
$$

where $\mathrm{F}_{1}, \mathrm{~F}_{2}$, h are as in Example 1, does not have a solution. In fact, there does not exist a function $\beta: \mathrm{K}_{2} \rightarrow \mathrm{K}_{1}$ for which $\mathbb{R}=\mathrm{G}_{22} \subset \mathrm{G}_{1 \beta(\mathrm{k})}=\mathrm{G}_{11}=\{0\}$.

We prove this fact directly, too. We have $f\left[F_{2}(0, t)\right]=f(0) \neq F_{1}(f(0), t)$ since $F_{1}(f(0), \mathbb{R})=\left(-\frac{\pi}{2}, \frac{\pi}{2}\right)$.

3. Let the function $\mathrm{F}$ be of the form

$$
F(x, t)= \begin{cases}b_{n}^{-1}\left[b_{n}(x)+t\right] & \text { for } x \in S_{n}, t \in G, \\ x & \text { for } x \in S \backslash \cup S_{n}=: N_{2}, t \in G,\end{cases}
$$

where $\mathrm{G}$ is an abelian group, $\mathrm{S}_{\mathrm{n}}$ are disjoint subsets of $\mathrm{S}$ such that $\operatorname{card}_{\mathrm{n}}=$ cardG for $n$ in a set $N_{1}$ of indices which is disjoint with $N_{2}$ and $h_{n}: S_{n} \rightarrow G$ are bijections.

Consider the equation

$$
\mathrm{f}[\mathrm{F}(\mathrm{x}, \mathrm{t})]=\mathrm{F}(\mathrm{f}(\mathrm{x}), \mathrm{t}) .
$$

Put $\mathrm{N}=\mathrm{N}_{1} \cup \mathrm{N}_{2}$. The formula

$$
f(x)= \begin{cases}\gamma(x) & \text { for } x \in N_{2}, \\ \gamma(n) & \text { for } x \in S_{n}, \gamma(n) \in N_{2}, \\ b_{\gamma(n)}^{-1}\left[b_{n}(x)+\delta(n)\right] & \text { for } x \in S_{n}, \gamma(n) \in N_{1},\end{cases}
$$

where the function $\gamma: \mathrm{N} \rightarrow \mathrm{N}$ is such that $\gamma\left(\mathrm{N}_{2}\right) \subset \mathrm{N}_{2}$ and $\delta$ is an arbitrary function from $\mathrm{N}_{1}$ to $\mathrm{G}$, gives all the solutions of (7).

For the proof assume that the function $\mathrm{f}: \mathrm{S} \rightarrow \mathrm{S}$ is a solution of (7). If $\mathrm{x} \in \mathrm{S} \backslash \cup \mathrm{S}_{\mathrm{n}}=\mathrm{N}_{2}$, then $\mathrm{f}(\mathrm{x})=\mathrm{f}[\mathrm{F}(\mathrm{x}, \mathrm{t})]=\mathrm{F}(\mathrm{f}(\mathrm{x}), \mathrm{t})$, thus $\mathrm{f}(\mathrm{x}) \in \mathrm{N}_{2}$ and we put $\gamma(\mathrm{x})=\mathrm{f}(\mathrm{x})$.

If $x \in S_{n}$ and $f(x) \in N_{2}$, then we have $f[F(x, t)\}=F(f(x), t)=f(x)$. This yields that $\mathrm{f}$ is a constant function on $\mathrm{S}_{\mathrm{n}}$ and this constant, denoted $\gamma(\mathrm{n})$, is in $\mathrm{N}_{2}$. From here $f(x)=\gamma(n)$ for $x \in S_{n}$.

If $x \in S_{n}$ and $f(x) \in \cup I_{n}$, then $f(x) \in S_{m}$ for some $m \in N_{1}$. Since $f[F(x, t)]=$ $\mathrm{F}(\mathrm{f}(\mathrm{x}), \mathrm{t}) \in \mathrm{S}_{\mathrm{m}}$, thus the values of the function $\mathrm{f}$ on $\mathrm{S}_{\mathrm{n}}$ are in $\mathrm{S}_{\mathrm{m}}$. From here $m$ is determined by $n$, thus $m$ is a function of $n: m=\gamma(n) \in N_{1}$. Let $x_{0}$ be a fixed point of $S_{n}$, then $f\left(x_{0}\right) \in S_{\gamma(n)}$. Since $x \in S_{n}$, for $\tau=b_{n}(x)-b_{n}\left(x_{0}\right)$ we have $\mathrm{F}\left(\mathrm{x}_{0}, \tau\right)=\mathrm{b}_{\mathrm{n}}^{-1}\left(\mathrm{~b}_{\mathrm{n}}\left(\mathrm{x}_{0}\right)+\tau\right)=\mathrm{x}$. This implies that

$$
\begin{aligned}
f(x) & =f\left[F\left(x_{0}, \tau\right)\right]=F\left(f\left(x_{0}\right), \tau\right)=b_{\gamma(n)}^{-1}\left[b_{\gamma(n)}\left(f\left(x_{0}\right)\right)+b_{n}(x)-b_{n}\left(x_{0}\right)\right] \\
& =b_{\gamma(n)}^{-1}\left(b_{n}(x)+\delta(n)\right),
\end{aligned}
$$

where $\delta(n)=b_{\gamma(\mathrm{n})}\left(\mathrm{f}\left(\mathrm{x}_{0}\right)\right)-\mathrm{b}_{\mathrm{n}}\left(\mathrm{x}_{0}\right)$ is a function from $\mathrm{N}_{1}$ to $\mathrm{G}$. 
It is easily to verify that a function of the form (8) is the solution of the Eq. (7).

This result is proven in [9] if $\mathrm{F}: \mathbb{R} \times \mathbb{R} \rightarrow \mathbb{R}$ is the continuous solution of the translation equation. Note that the formula (8) gives all the functions $f$ which are commutative with the functions of the family $\{\mathrm{F}(., \mathrm{t})\}_{\mathrm{t} \epsilon} \mathrm{G}$ of functions from $\mathrm{S}$ to $\mathrm{S}$.

If a solution $\mathrm{F}: \mathbb{R} \times \mathbb{R} \rightarrow \mathbb{R}$ of the translation equation, such that $\mathrm{F}(\mathrm{x}, 0)=\mathrm{x}$ for $x \in \mathbb{R}$, is continuous with respect to the second variable for every $x \in \mathbb{R}$ and for which at least one of the functions $F(., t): \mathbb{R} \rightarrow \mathbb{R}$ is continuous, then the function $\mathrm{F}$ has the form (6). In this case $S_{n}$ are open intervals and $b_{n}$ are homeomorphisms and the function $\mathrm{F}$ is continuous [10]. This solution $\mathrm{F}$ of the translation equation is continuous, too, if $\mathrm{F}$ is Carathéodory, i.e., the function $\mathrm{F}(\mathrm{x},):. \mathbb{R} \rightarrow \mathbb{R}$ is measurable for every $\mathrm{x} \in \mathbb{R}$ and function $\mathrm{F}(., \mathrm{t}): \mathbb{R} \rightarrow \mathbb{R}$ is continuos for every $t \in \mathbb{R}[2]$.

Recall that $\mathrm{x}_{0}$ is said to be a fixed point of the function $\mathrm{F}: \mathrm{S} \times \mathrm{G} \rightarrow \mathrm{G}$ if $\mathrm{F}\left(\mathrm{x}_{0}, \mathrm{t}\right)=\mathrm{x}_{0}$ for $\mathrm{t} \epsilon \mathrm{G}$.

Theorem 2. Let $F: \mathbb{R} \times \mathbb{R} \rightarrow \mathbb{R}$ be a continuous solution of the translation equation such that $F(x, 0)=x$ for $x \in \mathbb{R}$. Every solution $f$ of $(7)$ is continuous if and only if $F$ does not have any fixed points.

Proof. Assume that $\mathrm{f}$ is a solution of (7). If $\mathrm{F}$ does not have any fixed points, then the set $N_{1}$ in the form (8) of $F$ is a singelton $N_{1}=\{m\}$ and $S_{m}=\mathbb{R}$. From here $\gamma(\mathrm{m})=\mathrm{m}$ and $\mathrm{f}(\mathrm{x})=\mathrm{b}_{\mathrm{m}}^{-1}\left(\mathrm{~b}_{\mathrm{m}}(\mathrm{x})+\delta(\mathrm{m})\right)$ for $\mathrm{x} \in \mathbb{R}$, where $\mathrm{b}_{\mathrm{m}}: \mathbb{R} \rightarrow \mathbb{R}$ is a homeomorphism and $\delta(\mathrm{m}) \in \mathbb{R}$. The function $\mathrm{f}$ is thus continuous.

If $\mathrm{a}$ is the only fixed point of $\mathrm{F}$, i.e., $\mathrm{N}_{2}=\{\mathrm{a}\}$ in (6), then $\mathrm{N}_{1}$ has two elements, which we denote as 1,2 , so that $\mathrm{S}_{1}=(-\infty, \mathrm{a})$ and $\mathrm{S}_{2}=(\mathrm{a},+\infty)$. If $\gamma(1)=2, \gamma(2)=2, \gamma(\mathrm{a})=\mathrm{a}, \delta:\{1,2\} \rightarrow \mathbb{R}$ is an arbitrary function and $b_{1}: S_{1} \rightarrow \mathbb{R}$ and $b_{2}: S_{2} \rightarrow \mathbb{R}$ are arbitrary increasing bijections, then the function $\mathrm{f}$ defined as in (8) is a solution of $(7)$. For $\mathrm{x} \in \mathrm{S}_{1}$ we obtain $\mathrm{f}(\mathrm{x})=$ $\mathrm{b}_{2}^{-1}\left(\mathrm{~b}_{1}(\mathrm{x})+\delta(1)\right)$. We have for $\mathrm{x} \rightarrow \mathrm{a}$ that $\mathrm{b}_{1}(\mathrm{x})+\delta(1) \rightarrow+\infty$, thus $\mathrm{b}_{2}^{-1}\left(\mathrm{~b}_{1}(\mathrm{x})+\right.$ $\delta(1)) \rightarrow+\infty$ and from here $\mathrm{f}$ is not continuous.

Let $\mathrm{a}$ and $\mathrm{b}$ be two different fixed point of $\mathrm{F}$. We consider two cases.

a/ Every point of the interval $(a, b)$ is a fixed point of $\mathrm{F}$.

b/ The opposite case to a/.

In case $\mathrm{a} /$ let the function $\gamma$ in (8) be such that $\gamma(\mathrm{a})=\mathrm{b}$ and $\gamma(\mathrm{x})=\mathrm{x}$ for $\mathrm{x} \in(\mathrm{a}, \mathrm{b})$. From here we have for the function $\mathrm{f}$ defined as in $(8)$ that

$$
\lim _{x \rightarrow a+} f(x)=a \neq b=\gamma(a)=f(a),
$$

thus $\mathrm{f}$ is discontinuous.

In case b/ there exists at least one $n \in \mathrm{N}_{1}$ in the form (6) of the function $\mathrm{F}$ such that $\mathrm{S}_{\mathrm{n}} \subset(\mathrm{a}, \mathrm{b})$. Let $\mathrm{c}=\operatorname{infS}_{\mathrm{n}}$. Then $c \in \mathrm{N}_{2}$. Let $\gamma$ in (8) be such that 
$\gamma(\mathrm{c})=\mathrm{b}, \gamma(\mathrm{n})=\mathrm{n}$ and let $\delta(\mathrm{n})=0$ in (8). From here $\mathrm{f}(\mathrm{x})=\mathrm{x}$ for $\mathrm{x} \in \mathrm{S}_{\mathrm{n}}$. This yields that

$$
\lim _{x \rightarrow c+} f(x)=c \neq b=\gamma(c)=f(c),
$$

thus $\mathrm{f}$ is discontinuous.

If in Eq. (7) we take the function $\mathrm{F}_{1}$ of Example 1 as the function $\mathrm{F}$, then the solution $\mathrm{f}$ has the form $\mathrm{f}(\mathrm{x})=\operatorname{tn}^{-1}(\operatorname{tnx}+\delta)$ for $\delta \in \mathbb{R}$. If in this equation we have $\mathrm{F}_{2}$, then

$$
f(x)= \begin{cases}0 & \text { for } x=0 \\ 0 & \text { for } x \in S_{n}, \gamma(n)=0 \\ b_{\gamma(n)}^{-1}\left(b_{n}(x)+\delta(n)\right) & \text { for } x \in S_{n}, \gamma(n) \neq 0\end{cases}
$$

where $S_{1}=(0,+\infty), S_{2}=(-\infty, 0), \gamma:\{0,1,2\} \rightarrow\{0,1,2\}, \gamma(0)=0, \delta:$ $\{1,2\} \rightarrow \mathbb{R}, \mathrm{b}_{1}(\mathrm{x})=\ln \mathrm{x}, \mathrm{b}_{2}(\mathrm{x})=\ln (-\mathrm{x})$.

4. The constant function $f(x)=c$ for $x \in S_{1}$ is a solution of (1) if and only if $\mathrm{F}_{2}(\mathrm{c}, \mathrm{h}(\mathrm{t}))=\mathrm{c}$ for $\mathrm{t} \in \mathrm{G}_{1}$. We verify condition (3) directly in this case. If $\mathrm{f}(\mathrm{x})=c \in \mathrm{S}_{2}$ is a solution of (1), then there exists a $l \in \mathrm{K}_{2}$ such that $c \in \mathrm{S}_{21}$. From here $\mathrm{F}_{2}(\mathrm{c}, \mathrm{s})=\mathrm{b}_{21}^{-1}\left[\mathrm{~b}_{21}(\mathrm{c})+\mathrm{s}\right]$ thus $\mathrm{c}=\mathrm{F}_{2}(\mathrm{c}, \mathrm{h}(\mathrm{t}))=\mathrm{b}_{21}^{-1}\left[\mathrm{~b}_{21}(\mathrm{c})+\mathrm{h}(\mathrm{t})\right]$ for $t \in G_{1}$. There exists $s_{0} \in G_{2}$ for which $b_{21}(c)=G_{21}+s_{0}$. This yields that $\mathrm{G}_{21}+\mathrm{s}_{0}=\mathrm{b}_{21}(\mathrm{c})=\mathrm{G}_{21}+\mathrm{s}_{0}+\mathrm{h}(\mathrm{t})$. From here $-\mathrm{s}_{0}+\mathrm{G}_{21}+\mathrm{s}_{0}=\left(-\mathrm{s}+\mathrm{G}_{21}+\right.$ $\left.\mathrm{s}_{0}\right)+\mathrm{h}(\mathrm{t})$. Since $-\mathrm{s}_{0}+\mathrm{G}_{21}+\mathrm{s}_{0}$ is a group, $\mathrm{h}\left(\mathrm{G}_{1}\right) \subset\left[-\mathrm{s}_{0}+\mathrm{G}_{21}+\mathrm{s}_{0}\right]$. We have $\mathrm{h}\left(\mathrm{G}_{1 \mathrm{k}}\right) \subset \mathrm{h}\left(\mathrm{G}_{1}\right)$ for $\mathrm{k} \in \mathrm{K}_{1}$, thus the condition (3) is satisfied with $\beta(\mathrm{k})=\mathrm{s}_{0}$ for $\mathrm{k} \in \mathrm{K}$.

5. Consider the equation

$$
\mathrm{f}(\mathrm{g}(\mathrm{x}))=\mathrm{g}(\mathrm{f}(\mathrm{x})),
$$

where $\mathrm{g}: \mathrm{S} \rightarrow \mathrm{S}$ is a given idempotent function and $\mathrm{f}: \mathrm{S} \rightarrow \mathrm{S}$ is the unknown function. This is an equation of the form (1) for $F_{1}(x, t)=F_{2}(x, t)=g(x)$.

If $g$ is an injective function on the set $S \backslash g(S)$, then every function $f$ of of the form

$$
f(x)= \begin{cases}f_{1}(x) & \text { for } x \in g(S), \\ g_{1}^{-1}\left[f_{1}(g(x)]\right. & \text { for } x \in S \backslash g(S),\end{cases}
$$

where $f_{1}$ is an arbitrary function from $g(S)$ to $g(S)$ and $g_{1}=g_{\mid S \backslash g(S)}$, is a solution of (9).

Indeed, if $x \in g(S)$, then there exists $y \in S$ such that $x=g(y)$. From here $\mathrm{f}(\mathrm{g}(\mathrm{x}))=\mathrm{f}[\mathrm{g}(\mathrm{g}(\mathrm{y}))]=\mathrm{f}(\mathrm{g}(\mathrm{y}))=\mathrm{f}(\mathrm{x})=\mathrm{f}_{1}(\mathrm{x})=\mathrm{g}\left(\mathrm{f}_{1}(\mathrm{x})\right)=\mathrm{g}(\mathrm{f}(\mathrm{x}))$ since $\mathrm{g}$ is the identity on $g(S)$ as the idempotent. If $x \in S \backslash g(S)$, then $g(f(x))=f_{1}(g(x))=$ $\mathrm{f}(\mathrm{g}(\mathrm{x}))$ since $\mathrm{g}(\mathrm{x}) \in \mathrm{g}(\mathrm{S})$.

If $S=g(S)$, i.e., if $g(x)=x$ for $x \in S$, then every function $f: S \rightarrow S$ is a solution of (9). 
If $S \neq g(S)$, then a solution $f$ of (9) is of the form (10) if and only if $f(S \backslash g(S)) \subset S \backslash g(S)$. In fact, if $f$ is a solution of (9) and $f(S \backslash g(S)) \subset S \backslash g(S)$, then

a/ for $x \in g(S)$ we have $f(x)=f(g(x))=g(f(x)) \in g(S)$, thus $f_{1}=f_{\mid g(S)}$ is a function from $g(S)$ to $g(S)$ and $f=f_{1}$ on $g(S)$,

b/ for $x \in S \backslash g(S)$ we have $f(x) \epsilon S \backslash g(S)$ and $f(x)=g_{1}^{-1}\left[f_{1}(g(x)]\right.$ since

$$
\mathrm{g}_{1}(\mathrm{f}(\mathrm{x}))=\mathrm{g}(\mathrm{f}(\mathrm{x}))=\mathrm{f}(\mathrm{g}(\mathrm{x}))=\mathrm{f}_{1}(\mathrm{~g}(\mathrm{x})) .
$$

If $\mathrm{f}$ is of the form (10), then for $\mathrm{x} \in \mathrm{S} \backslash \mathrm{g}(\mathrm{S})$ we obtain $\mathrm{f}(\mathrm{x})=\mathrm{g}_{1}^{-1}\left[\mathrm{f}_{1}(\mathrm{~g}(\mathrm{x})] \epsilon\right.$ $\mathrm{S} \backslash \mathrm{g}(\mathrm{S})$.

Note in the end that if $S \neq g(S)$, then the function $f(x)=c \in g(S)$ for $x \in S$ is a solution of (9) and $\mathrm{f}$ is not of the form (10) by the above.

6. Let $\mathrm{G}$ be the groupoid of $\mathrm{n} \times \mathrm{n}$-matrices with the usual multiplication. We give all the solutions of Eq. (7) in which $F(x, t)=x t: \mathbb{R}^{n} \times G \rightarrow \mathbb{R}^{n}$ (the transformation law of the vector). Equation (7) is in this case of the form $\mathrm{f}(\mathrm{xt})=\mathrm{f}(\mathrm{x}) \mathrm{t}$. Assume that a function $\mathrm{f}: \mathbb{R}^{\mathrm{n}} \rightarrow \mathbb{R}^{\mathrm{n}}$ is a solution of this equation. Put in this equation $\mathrm{x}=(1,0, \ldots, 0)$ and $t=\left\|\mathrm{t}_{\mathrm{ik}}\right\|_{\mathrm{i}, \mathrm{k}=1, \ldots, \mathrm{n}}$, where $t_{1 \mathrm{k}}=\mathrm{x}_{\mathrm{k}}$ for $\mathrm{k}=1, \ldots, \mathrm{n}$ and the other $\mathrm{t}_{\mathrm{ik}}$ are arbitrary in $\mathbb{R}$, we have $\mathrm{f}\left(\mathrm{x}_{1}, \ldots, \mathrm{x}_{\mathrm{n}}\right)=\left(\mathrm{y}_{1}, \ldots, \mathrm{y}_{\mathrm{n}}\right) \mathrm{t}$, where $\mathrm{y}:=\left(\mathrm{y}_{1}, \ldots, \mathrm{y}_{\mathrm{n}}\right)=\mathrm{f}(1,0, \ldots, 0)$. Assume that there exists $\mathrm{m} \neq 1$ for which $\mathrm{y}_{\mathrm{m}} \neq 0$. Let $\mathrm{a}_{1}=\left\|\mathrm{a}_{\mathrm{ik}}\right\|_{\mathrm{i}, \mathrm{k}=1, \ldots, \mathrm{n}}$, where $\mathrm{a}_{1 \mathrm{k}}=\mathrm{x}_{\mathrm{k}}$ for $\mathrm{k}=1, \ldots, \mathrm{n}, \mathrm{a}_{\mathrm{i} 1}=0$ for $\mathrm{i} \neq 1$ and the other $\mathrm{a}_{\mathrm{ik}}$ are arbitrary in $\mathbb{R}$. Let $\mathrm{a}_{2}=\left\|\mathrm{b}_{\mathrm{ik}}\right\|_{\mathrm{i}, \mathrm{k}=1, \ldots, \mathrm{n}}$, where $\mathrm{b}_{1 \mathrm{k}}=\mathrm{x}_{\mathrm{k}}$ for $\mathrm{k}=1, \ldots, \mathrm{n}$, $\mathrm{b}_{\mathrm{m} 1}=1, \mathrm{~b}_{\mathrm{i} 1}=0$ for $\mathrm{i} \neq 1, \mathrm{~m}$ and the other $\mathrm{b}_{\mathrm{ik}}$ are arbitrary in $\mathbb{R}$. Puting $\mathrm{t}=\mathrm{a}_{\mathrm{l}}$ in our equation we have $\mathrm{f}\left(\mathrm{x}_{1}, \ldots, \mathrm{x}_{\mathrm{n}}\right)=\mathrm{ya}_{\mathrm{l}}$. From here $\mathrm{ya}_{1}=\mathrm{ya}_{2}$ and in particular

$$
\begin{aligned}
\mathrm{y}_{1} \mathrm{x}_{1} & =\mathrm{y}_{1} \mathrm{a}_{11}+\mathrm{y}_{2} \mathrm{a}_{21}+\cdots+\mathrm{y}_{\mathrm{n}} \mathrm{a}_{\mathrm{n} 1}=\mathrm{y}_{1} \mathrm{~b}_{11}+\cdots+\mathrm{y}_{\mathrm{m}} \mathrm{b}_{\mathrm{m} 1}+\cdots \\
& +\mathrm{y}_{\mathrm{n}} \mathrm{b}_{\mathrm{n} 1}=\mathrm{y}_{1} \mathrm{x}_{1}+\mathrm{y}_{\mathrm{m}},
\end{aligned}
$$

thus $\mathrm{y}_{\mathrm{m}}=0$. We have a contradiction thus $\mathrm{y}_{\mathrm{i}}=0$ for $\mathrm{i}=2, \ldots, \mathrm{n}$. This yields, by the equation, that $\mathrm{f}\left(\mathrm{x}_{1}, \ldots, \mathrm{x}_{\mathrm{n}}\right)=\mathrm{y}_{1}\left(\mathrm{x}_{1}, \ldots, \mathrm{y}_{\mathrm{n}}\right)$. These functions are evidently solutions of our equation.

We have the same result if $\mathrm{G}$ is the group of nonsingular $\mathrm{n} \times \mathrm{n}$-matrices. We prove this for $n=2$. If we put in the above

$$
\begin{aligned}
& \text { i/ } \mathrm{a}_{1}=\left\|\begin{array}{cc}
x_{1} & x_{2} \\
0 & 1
\end{array}\right\| \text { and } \mathrm{a}_{2}=\left\|\begin{array}{cc}
x_{1} & x_{2} \\
1 & x_{2} x_{1}^{-1}+1
\end{array}\right\| \text { for } \mathrm{x}_{1} \neq 0 \text { and } \\
& \text { ii } / \mathrm{a}_{1}=\left\|\begin{array}{cc}
x_{1} & x_{2} \\
1 & 0
\end{array}\right\| \text { and } \mathrm{a}_{2}=\left\|\begin{array}{cc}
x_{1} & x_{2} \\
x_{1} x_{2}^{-1}+1 & 1
\end{array}\right\| \text { for } \mathrm{x}_{2} \neq 0 \text {, }
\end{aligned}
$$

then we obtain as above $\mathrm{y}_{2}=0$. Thus by the equation for $\mathrm{t}$ nonsingular (e,g., for $\left.\mathrm{t}=\left\|\begin{array}{cc}x_{1} & x_{2} \\ -x_{2} & x_{1}\end{array}\right\|\right)$ we have $\mathrm{f}\left(\mathrm{x}_{1}, \mathrm{x}_{2}\right)=\mathrm{y}_{1}\left(\mathrm{x}_{1}, \mathrm{x}_{2}\right)$ for $x_{1}^{2}+x_{2}^{2} \neq 0$. 
For $\left(\mathrm{x}_{1}, \mathrm{x}_{2}\right)=(0,0)$ put in our equation $\mathrm{t}=\| \begin{array}{ll}1 & 1 \\ 1 & 0\end{array} \mid$ and $\mathrm{f}((0,0))=(\alpha, \beta)$. Then we have $(\beta, \alpha-\beta)=(0,0)$, thus $\alpha=\beta=0$ and from here $f((0,0))=$ $(0,0)=\mathrm{y}_{1}(0,0)$, too.

It is possible to obtain this result also by the method as in Theorem 1 [9]. The above result means in the theory of geometric objects that the multiplication of a vector by a scalar is the only geometric concomitant of the vector.

\section{Unknown function $F_{2}$}

We only need to define the function $F_{2}$ on $S_{2} \times h\left(G_{1}\right)$ due to the form of the Eq. (1)

Theorem 3. 1/ Equation (1) has a solution for $F_{2}: S_{2} \times h\left(G_{1}\right) \rightarrow S_{2}$ if and only if

$$
f(x)=f(y) \text { and } h(t)=h(s) \Rightarrow f\left[F_{1}(x, t)\right]=f\left[F_{1}(y, s)\right] \text { for } x, y \in S_{1}, t, s \in G_{1} .
$$

2/ Let functions f, $h, F_{1}$ satisfy (11). Then a function of the form

$$
F_{2}(u, v)= \begin{cases}f\left[F_{1}(x, t)\right] & \text { for } u=f(x), v=h(t) \\ H(u, v) & \text { for } u \in S_{2} \backslash f\left(S_{1}\right), v \in h\left(G_{1}\right),\end{cases}
$$

where $H(u, v):\left(S_{2} \backslash f\left(S_{1}\right)\right) \times G_{1} \rightarrow S_{2} \backslash f\left(S_{1}\right)$ is an arbitrary solution of the translation equation, is a solutions of (1).

Proof. The proof of the "only if" part is evident.

The function $\mathrm{F}_{2}$ defined by (12) is well-defined due to (11) and it is a solution of (1). Moreover, for $\mathrm{u}=\mathrm{f}(\mathrm{x}), \mathrm{v}=\mathrm{h}(\mathrm{t}), \mathrm{w}=\mathrm{h}(\mathrm{s})$, we have

$$
\begin{aligned}
\mathrm{F}_{2}\left(\mathrm{~F}_{2}(\mathrm{u}, \mathrm{v}), \mathrm{w}\right) & =\mathrm{F}_{2}\left[\mathrm{~F}_{2}(\mathrm{f}(\mathrm{x}), \mathrm{h}(\mathrm{t})), \mathrm{h}(\mathrm{s})\right]=\mathrm{F}_{2}\left[\mathrm{f}\left(\mathrm{F}_{1}(\mathrm{x}, \mathrm{t})\right), \mathrm{h}(\mathrm{s})\right] \\
& =\mathrm{f}\left[\mathrm{F}_{1}\left(\mathrm{~F}_{1}(\mathrm{x}, \mathrm{t}), \mathrm{s}\right)\right]=\mathrm{f}\left[\mathrm{F}_{1}(\mathrm{x}, \mathrm{t}+\mathrm{s})\right]=\mathrm{F}_{2}(\mathrm{u}, \mathrm{v}+\mathrm{w}) .
\end{aligned}
$$

Example. $\quad$ 7. The condition (11) is satisfied for $\mathrm{h}(\mathrm{t})=\mathrm{t}$ and by every $\mathrm{f}(\mathrm{x})=$ $\varepsilon \exp (\mathrm{a}+\operatorname{tnx})(\varepsilon=-1,0,1)$ in the equation in Example 1

a/ since the function $h$ and the functions $f$ for $\varepsilon \neq 0$ are injective and for $\mathrm{f}=0(\varepsilon=0)$ the condition (11) is evident or

$\mathrm{b} /$ since there exist function $\mathrm{f}, \mathrm{h}, \mathrm{F}_{1}, \mathrm{~F}_{2}$ which satisfy equation (7).

If we want to have $\mathrm{F}_{2}$ defined on $\mathrm{S}_{2} \times \mathrm{G}_{2}$, then we must extend the solution $\mathrm{F}_{2}$ of the translation equation on $\mathrm{S}_{2} \times \mathrm{h}\left(\mathrm{G}_{1}\right)$ to the solution of the translation equation on $\mathrm{S}_{2} \times \mathrm{G}_{2}$. This extension is not always possible (see Example 8 below). For the condition when this extension is possible see [6] and [8]. 
Examples. 8. Let $\mathrm{S}_{1}=\mathrm{S}_{2}=\mathbb{Z}, \mathrm{G}_{1}=\mathrm{G}_{2}=\mathbb{Z}$ (the additive group of integers $), f(x)=x, h(t)=2 t, F_{1}(x, t)=x+t$. These functions evidently satisfy (11). Assume that there exists a solution $\mathrm{F}_{2}: \mathbb{Z} \times \mathbb{Z} \rightarrow \mathbb{Z}$ of the translation equation such that $\mathrm{F}_{2}(\mathrm{x}, \mathrm{u})=\mathrm{F}(\mathrm{x}, \mathrm{t})$ for $\mathrm{u}=2 \mathrm{t}$, i.e., such that $\mathrm{F}_{2}(\mathrm{x}, 2 \mathrm{t})=\mathrm{F}_{1}(\mathrm{x}, \mathrm{t})=\mathrm{x}+\mathrm{t}$ for $(\mathrm{x}, \mathrm{t}) \in \mathbb{Z} \times \mathbb{Z}$. From here we have for $\mathrm{x} \in \mathbb{Z}$

$$
\mathbb{Z}=\mathrm{F}_{1}(\mathrm{x}, \mathbb{Z})=\mathrm{F}_{2}(\mathrm{x}, 2 \mathbb{Z}) \subset \mathrm{F}_{2}(\mathrm{x}, \mathbb{Z}) \subset \mathbb{Z} \text {. }
$$

Thus $\mathrm{F}_{2}(\mathrm{x}, \mathbb{Z})=\mathbb{Z}$. Since $\mathrm{F}_{2}$ is the solution of the translation equation and $\mathrm{F}_{2}(\mathrm{x}, 0)=\mathrm{x}$ for $\mathrm{x} \in \mathbb{Z}, \mathrm{F}_{2}(\mathrm{x}, \mathrm{t})=\mathrm{b}_{1}^{-1}\left(\mathrm{~b}_{1}(\mathrm{x})+\mathrm{t}\right)$, where $\mathrm{b}_{1}$ is a bijection from $\mathbb{Z}$ to $\mathbb{Z} / \mathbb{Z}^{*}$ for a subgroup $\mathbb{Z}^{*}$ of $\mathbb{Z}[7]$. We have $b_{1}(0)=\mathbb{Z}^{*}+$ a for some a $\in \mathbb{Z}$. We obtain for $\mathrm{b}(\mathrm{x}):=\mathrm{b}_{1}(\mathrm{x})-\mathrm{a}$ that

$$
\mathrm{F}_{2}(\mathrm{x}, \mathrm{t})=\mathrm{b}_{1}^{-1}\left(\mathrm{~b}_{1}(\mathrm{x})+\mathrm{t}\right)=\mathrm{b}^{-1}(\mathrm{~b}(\mathrm{x})+\mathrm{t}) \text { and } \mathrm{b}(0)=\mathbb{Z}^{*} .
$$

This yields that $\mathrm{b}^{-1}(\mathrm{~b}(\mathrm{x})+2)=\mathrm{F}_{2}(\mathrm{x}, 2)=\mathrm{F}_{1}(\mathrm{x}, 1)=\mathrm{x}+1$. From here $\mathrm{b}(\mathrm{x})+2=\mathrm{b}(\mathrm{x}+1)$, thus $\mathrm{b}(1)=\mathrm{b}(0)+\mathbb{Z}^{*}$. This implies that $\mathrm{b}(\mathrm{x})=\mathbb{Z}^{*}+2 \mathrm{x}$ for $x \in \mathbb{Z}$. Let $c \geq 0$ be the generator of $\mathbb{Z}^{*}$, i.e., $\mathbb{Z}^{*}=\{$ nc:n $\in \mathbb{Z}\}$.

i/ If $\mathrm{c}=0$, i.e., $\mathbb{Z}^{*}=\{0\}$, then $\mathrm{b}(\mathrm{x})=\{0\}+2 \mathrm{x}$. From here $\mathrm{b}$ is not $\mathrm{a}$ function onto $\mathbb{Z} / \mathbb{Z}^{*}$.

ii/ If $\mathrm{c}>0$, then $\mathrm{b}(\mathrm{c})=\mathbb{Z}^{*}+2 \mathrm{c}=\mathbb{Z}^{*}=\mathbb{Z}^{*}+4 \mathrm{c}=\mathrm{b}(2 \mathrm{c})$. Thus the function $\mathrm{b}$ is not injective.

9. Let $S_{1}=S_{2}=G_{1}=G_{2}=G$ be a semigrup and $f(x)=x$ for $x \in G$. Let $\mathrm{h}: \mathrm{G} \rightarrow \mathrm{G}$ be a homomorphism such that $\mathrm{h}(\mathrm{G}) \neq \mathrm{G}$ and $\mathrm{F}_{1}(\mathrm{x}, \mathrm{t})=\mathrm{x}+\mathrm{h}(\mathrm{t})$ for $x, t \in G$. The function $F_{1}$ is the solution of the translation equation and $F_{1}$ satifies (11). The function $F_{2}$, definied on $\mathrm{G} \times \mathrm{h}(\mathrm{G})$ as in (12) (with $\mathrm{f}(\mathrm{x})=\mathrm{x})$, is of the form $\mathrm{F}_{2}(\mathrm{x}, \mathrm{h}(\mathrm{t}))=\mathrm{F}_{1}(\mathrm{x}, \mathrm{t})=\mathrm{x}+\mathrm{h}(\mathrm{t})$. Thus the function $\mathrm{x}+\mathrm{t}$ is an extention of $\mathrm{F}_{2}$ on the set $\mathrm{G} \times \mathrm{G}$.

Remarks. It is possible that the functions of the form (12) are not all the solutions of Eq. (1). E.g., if $\mathrm{S}_{1}=\mathrm{S}_{2}=\mathbb{R}, \mathrm{G}_{1}=\mathrm{G}_{2}=\mathbb{R}$ with the usual addition, $\mathrm{h}(\mathrm{t})=\mathrm{t}, \mathrm{f}(\mathrm{x})=\operatorname{expx}, \mathrm{F}_{1}(\mathrm{x}, \mathrm{t})=\mathrm{x}, \mathrm{F}_{2}(\mathrm{u}, \mathrm{v})=\mathrm{u}$ for $\mathrm{u}>0, \mathrm{v} \in \mathbb{R}$ and $\mathrm{F}_{2}(\mathrm{u}, \mathrm{v})=1$ for $\mathrm{u} \leq 0, \mathrm{v} \in \mathbb{R}$, then the solution of the translation equation $\mathrm{F}_{2}$ is the solution of (1), too. This function $\mathrm{F}_{2}$ is not of the form (12) since $0 \epsilon \mathrm{S}_{2} \backslash \mathrm{f}\left(\mathrm{S}_{1}\right)=(-\infty, 0]$ and $\mathrm{F}_{2}(0, \mathrm{v})=1 \notin \mathrm{S}_{2} \backslash \mathrm{f}\left(\mathrm{S}_{1}\right)$.

If $\mathrm{f}\left(\mathrm{S}_{1}\right)=\mathrm{S}_{2}$, then $\mathrm{F}_{2}$ must be of the form $\mathrm{F}_{2}(\mathrm{u}, \mathrm{v})=\mathrm{f}\left[\mathrm{F}_{1}(\mathrm{x}, \mathrm{t})\right]$ for $\mathrm{u}=\mathrm{f}(\mathrm{x})$, $\mathrm{v}=\mathrm{h}(\mathrm{t})$, thus Eq. (1) has only one solution. In this case if there exists $\mathrm{t}_{0}$ such that $\mathrm{F}_{1}\left(\mathrm{x}, \mathrm{t}_{0}\right)=\mathrm{x}$ for $\mathrm{x} \in \mathrm{S}_{1}$, then $\mathrm{F}_{2}\left(\mathrm{u}, \mathrm{h}\left(\mathrm{t}_{0}\right)\right)=\mathrm{f}(\mathrm{x})=\mathrm{u}$ for $\mathrm{u} \in \mathrm{S}_{2}$. From here if $F_{1}$ is the transformation law for a geometric object, then $F_{2}$ is the same.

If $\mathrm{S}_{1}=\mathrm{S}_{2}$, then for the function

$$
F_{2}(u, v)= \begin{cases}f\left[F_{1}(x, t)\right] & \text { for } u=f(x), v=h(t), \\ u & \text { for } u \in S_{2} \backslash f\left(S_{1}\right), v \in G_{2}\end{cases}
$$

we have the same situation as above. 
The condition (11) and the equation

$$
\mathrm{f}\left[\mathrm{F}_{1}(\mathrm{x}, \mathrm{t})\right]=\mathrm{F}_{1}(\mathrm{f}(\mathrm{x}), \mathrm{h}(\mathrm{t}))
$$

are not equivalent. A solution of this equation is a solution of (11) but not vice versa. E.g., every constant function $\mathrm{f}$ is a solution of (11) and $\mathrm{f}(\mathrm{x})=\mathrm{c}$ is a solution of the above equation if and only if $\mathrm{F}_{1}(\mathrm{c}, \mathrm{h}(\mathrm{t}))=\mathrm{c}$ for $\mathrm{t} \epsilon \mathrm{G}$.

\section{Unknown function $F_{1}$}

If the function $\mathrm{f}$ is injective, then the function $\mathrm{F}_{1}(\mathrm{x}, \mathrm{t})=\mathrm{f}^{-1}\left[\mathrm{~F}_{2}(\mathrm{f}(\mathrm{x}), \mathrm{h}(\mathrm{t}))\right]$ is the only solution of (1).

There exists solutions of (1) for a non-injective function $\mathrm{f}$.

Examples. 10. If $\mathrm{f}(\mathrm{x})=\mathrm{c}, \mathrm{F}_{2}$ is a solution of the translation equation such that $\mathrm{c}$ is a fixed point of $\mathrm{F}_{2}\left(\mathrm{~F}_{2}(\mathrm{c}, \mathrm{v})=\mathrm{c}\right.$ for $\left.\mathrm{v} \in \mathrm{G}_{2}\right)$ and $\mathrm{h}$ is an arbitrary homomorphism, then every function $\mathrm{F}_{1}: \mathrm{S}_{1} \times \mathrm{G}_{1} \rightarrow \mathrm{S}_{1}$ is a solution of (1).

A function $\mathrm{F}_{1}: \mathrm{S}_{1} \times \mathrm{G}_{1} \rightarrow \mathrm{S}_{1}$ is the solution of (1) only if $\mathrm{f}(\mathrm{x})=\mathrm{f}(\mathrm{y}) \Rightarrow \mathrm{f}\left(\mathrm{F}_{1}(\mathrm{x}, \mathrm{t})\right)=\mathrm{f}\left(\mathrm{F}_{1}(\mathrm{y}, \mathrm{t})\right)$ for $\mathrm{x}, \mathrm{y} \in \mathrm{S}_{1}, \mathrm{t} \in \mathrm{G}_{1}$.

Note that the solution $\mathrm{F}_{1}(\mathrm{x}, \mathrm{t})=\mathrm{c}$ for $(\mathrm{x}, \mathrm{t}) \in \mathrm{S}_{1} \times \mathrm{G}_{1}$ of the above condition is a solution of (1) only if $F_{2}(f(x), h(t))=f(c)$ for $(x, t) \in S_{1} \times G_{1}$.

11. Let $\mathrm{F}_{\mathrm{i}}: \mathrm{S}_{\mathrm{i}} \times \mathrm{G}_{\mathrm{i}} \rightarrow \mathrm{S}_{\mathrm{i}}$ for $\mathrm{i}=1,2$ be arbitrary functions not necessarily a solutions of the translation equation. Consider a special case of equation (11) namely if $F_{2}$ is such that $F_{2}(u, v)=u$ on $f\left(S_{1}\right) \times h\left(G_{1}\right)$. Then Eq. (11) has the form

$$
\mathrm{f}\left(\mathrm{F}_{1}(\mathrm{x}, \mathrm{t})\right)=\mathrm{f}(\mathrm{x}) .
$$

In this case the function $\mathrm{F}_{1}$, such that $\mathrm{x} \in \mathrm{F}_{1}\left(\mathrm{x}, \mathrm{G}_{1}\right)$ for $\mathrm{x} \in \mathrm{S}_{1}$, is a solution of (11) if and only if the set $F_{1}\left(x, G_{1}\right)$ is included in some level of the function $f$ for every $\mathrm{x} \in \mathrm{S}_{1}$.

From here the function $\mathrm{F}_{1}$ of the form as in (2) satisfisies Eq. (13) if and only if for every $k \in K_{1}$ the set $S_{1 k}$ is included in some level of $f$.

E.g., let $S_{1}=\mathbb{R}$ and $f(x)=|x|$. The levels of $f$ have the form $\{-a, a\}$ for $a \in \mathbb{R}$. Assume that the group $G_{1}$ is non-orientable, i.e., there exists no subgroup of $\mathrm{G}_{1}$ with index 2 (e.g., the additive group $\mathbb{R}$ is non-orientable). Thus it is impossible that $S_{1 \mathrm{k}}=\{-\mathrm{a}, \mathrm{a}\}$ for $\mathrm{a} \neq 0$. From here every $\mathrm{S}_{1 \mathrm{k}}$ in the form $\mathrm{F}_{1}$ in (2) is a singelton. This yields that the constant functions $\mathrm{F}_{1}(\mathrm{x}, \mathrm{t})=\mathrm{c} \in \mathbb{R}$ are the only solutions of (13) in this case.

Let $\mathrm{S}_{1}$ and $\mathrm{f}$ be as above. Assume that $\mathrm{G}_{1}$ is orientable by the subgroup $G_{1}^{*}$ (like the additive group of integers by even integers). We have in this case, 
except for the constant solutions, the non-constant solutions of (13), too, e.g., the solution of the form

$$
\mathrm{F}_{1}(\mathrm{x}, \mathrm{t})= \begin{cases}-1 & \text { for } \mathrm{x}=-1, \mathrm{t} \in G_{1}^{*} \text { or or } \mathrm{x}=1, \mathrm{t} \in \mathrm{G}_{1} \backslash G_{1}^{*}, \\ 1 & \text { for } \mathrm{x}=-1, \mathrm{t} \in \mathrm{G}_{1} \backslash G_{1}^{*} \text { or } \mathrm{x}=1, \mathrm{t} \in G_{1}^{*}, \\ \mathrm{c} \in \mathbb{R} & \text { for } \mathrm{x} \in \mathbb{R} \backslash\{-1,1\}, \mathrm{t} \in \mathrm{G}_{1} .\end{cases}
$$

\section{Unknown homomorphism h}

Theorem 4. If a function $F: S \times G \rightarrow S$ is of the form (6) and function $f$ is of the form (8), then the equation

$$
f[F(x, t)]=F(f(x), h(t))
$$

has $h(t)=t$ as the only solution if $\gamma\left(N_{1}\right) \not \subset N_{2}$.

If $\gamma\left(N_{1}\right) \subset N_{2}$, then every function $h: G \rightarrow G$ is a solution of (14).

Proof. If $\gamma\left(\mathrm{N}_{1}\right) \not \subset \mathrm{N}_{2}$, then there exists $m \in \mathrm{N}_{1}$ such that $\gamma(\mathrm{m}) \in \mathrm{N}_{1}$. Assume that the function $h$ is a solution of (1). Then for $x \in I_{m}$ we have $f(x)=b_{\gamma(m)}^{-1}\left[b_{m}(x)+\right.$ $\delta(\mathrm{m})] \epsilon \mathrm{S}_{\gamma(\mathrm{m})}, \mathrm{F}(\mathrm{x}, \mathrm{t})=\mathrm{b}_{\mathrm{m}}^{-1}\left[\mathrm{~b}_{\mathrm{m}}(\mathrm{x})+\mathrm{t}\right] \epsilon \mathrm{S}_{\mathrm{m}}$. From here (14) has the form

$$
\mathrm{b}_{\gamma(\mathrm{m})}^{-1}\left[\mathrm{~b}_{\mathrm{m}}(\mathrm{x})+\mathrm{t}+\delta(\mathrm{m})\right]=\mathrm{b}_{\gamma(\mathrm{m})}^{-1}\left[\mathrm{~b}_{\mathrm{m}}(\mathrm{x})+\delta(\mathrm{m})+\mathrm{h}(\mathrm{t})\right]
$$

thus $\mathrm{h}(\mathrm{t})=\mathrm{t}$. This homomorphism is a solution of (1) by Example 3 .

If $\gamma\left(N_{1}\right) \subset N_{2}$, then $\gamma(n) \in N_{1}$ for every $n \in N$. From here for every function $\mathrm{h}: \mathrm{G} \rightarrow \mathrm{G}$

$1 /$ if $x \in N_{2}$, then $f(x)=\gamma(x)$ and we obtain $f[F(x, t)]=f(x)=\gamma(x)=$ $\mathrm{F}(\gamma(\mathrm{x}), \mathrm{h}(\mathrm{t}))$,

$2 /$ if $x \in I_{n}$, then $f(x)=\gamma(n)$ and since $F(x, t) \in I_{n}$ we obtain $f[F(x, t)]=\gamma(x)=$ $\mathrm{F}(\gamma(\mathrm{x}), \mathrm{h}(\mathrm{t}))=\mathrm{F}(\mathrm{f}(\mathrm{x}), \mathrm{h}(\mathrm{t}))$.

Proposition. Let functions $F_{\mathrm{i}}$ be as in (2). If there exists $x_{0} \in S_{1}$ such that $F_{1}\left(x_{0},.\right): G_{1} \rightarrow S_{1}$ is a constant function and $F_{2}\left(f\left(x_{0}\right),.\right): G_{2} \rightarrow S_{2}$ is an injection, then $h(t)=0$ for $t \in G_{1}$ is the only solution of (1).

The function $h(t)=0$ for $t \in G_{1}$ is a solution of (1) if and only if the function $f$ is constant on every $S_{1 \mathrm{k}}$ for $k \in K_{1}$. In this case other solutions $h$ can exist.

Proof. We have $\mathrm{f}\left[\mathrm{F}_{1}\left(\mathrm{x}_{0}, \mathrm{t}\right)\right]=\mathrm{f}\left[\mathrm{F}_{1}\left(\mathrm{x}_{0}, 0\right)\right]=\mathrm{f}\left(\mathrm{x}_{0}\right)$. For $\mathrm{f}\left(\mathrm{x}_{0}\right) \in \mathrm{S}_{2 \mathrm{k}}$ for some $\mathrm{k} \in \mathrm{K}_{2}$ we obtain $\mathrm{F}_{2}\left(\mathrm{f}\left(\mathrm{x}_{0}\right), \mathrm{h}(\mathrm{t})\right)=\mathrm{b}_{2 \mathrm{k}}^{-1}\left[\mathrm{~b}_{2 \mathrm{k}}\left(\mathrm{f}\left(\mathrm{x}_{0}\right)+\mathrm{h}(\mathrm{t})\right]\right.$, where $\mathrm{b}_{2 \mathrm{k}}$ is a bijection from $\mathrm{S}_{2 \mathrm{k}}$ onto $\mathrm{G}_{2}$. From here $\mathrm{b}_{2 \mathrm{k}}\left(\mathrm{f}\left(\mathrm{x}_{0}\right)\right)=\mathrm{b}_{2 \mathrm{k}}\left(\mathrm{f}\left(\mathrm{x}_{0}\right)\right)+\mathrm{h}(\mathrm{t})$. This yields that $\mathrm{h}(\mathrm{t})=0$ for $t \in \mathrm{G}_{1}$.

If $h(t)=0$, then $f\left[F_{1}(x, t)\right]=F_{2}(f(x), 0)=f(x)$. Since $F_{1}\left(x, G_{1}\right)=S_{1 k}$ for $x \in S_{1 k}, f$ is constant on $S_{1 k}$. The inverse implication is evident. If $f(x)=c \in S_{2}$ for $x \in S_{1}$ and $F_{2}(c, t)=c$ for $t \in G_{2}$, the every function $h: G_{1} \rightarrow G_{2}$ is a solution of (1). 
Lemma 1. Let $F: S \times G \rightarrow S$, where $G$ is a group, be a solution of the translation equation such that $F(x, 0)=x$ for $x \in S$. A function $g: G \rightarrow G$ (not necessarly a homomorphism) is a solution of the equation

$$
F(x, t)=F(x, g(t))
$$

if and only if $g(t)-t \in \cap_{\mathrm{x} \in \mathrm{S}}\{s \in G: F(x, s)=x\}$ for $t \in G$.

Proof. If $\mathrm{g}(\mathrm{t})-\mathrm{t} \in \cap_{\mathrm{x} \in \mathrm{S}}\{\mathrm{s} \in \mathrm{G}: \mathrm{F}(\mathrm{x}, \mathrm{s})=\mathrm{x}\}$, then

$$
\mathrm{F}(\mathrm{x}, \mathrm{g}(\mathrm{t}))=\mathrm{F}(\mathrm{F}(\mathrm{x}, \mathrm{g}(\mathrm{t})-\mathrm{t}), \mathrm{t})=\mathrm{F}(\mathrm{x}, \mathrm{t}) .
$$

If $\mathrm{F}(\mathrm{x}, \mathrm{g}(\mathrm{t}))=\mathrm{F}(\mathrm{x}, \mathrm{t})$, then $\mathrm{g}(\mathrm{t})-\mathrm{t} \epsilon \cap_{\mathrm{x} \in \mathrm{S}}\{\mathrm{s} \in \mathrm{G}: \mathrm{F}(\mathrm{x}, \mathrm{s})=\mathrm{x}\}$ since

$$
\mathrm{F}(\mathrm{x}, \mathrm{g}(\mathrm{t})-\mathrm{t})=\mathrm{F}(\mathrm{F}(\mathrm{x}, \mathrm{g}(\mathrm{t})),-\mathrm{t})=\mathrm{F}(\mathrm{F}(\mathrm{x}, \mathrm{t}),-\mathrm{t})=\mathrm{F}(\mathrm{x}, 0)=\mathrm{x} .
$$

Lemma 2. Let a function $F$ be of the form $F(x, t)=b_{k}^{-1}\left(b_{\mathrm{k}}(x)+t\right)$ for $x \in S_{\mathrm{k}}$, $k \in K, t \in G$, where $S=\cup_{\mathrm{k} \in \mathrm{K}} S_{\mathrm{k}}, S_{\mathrm{k}}$ are disjoint and $b_{\mathrm{k}}$ is a bijection from $S_{\mathrm{k}}$ to $G / G_{\mathrm{k}}($ see $(2))$. Then

$$
\cap_{\mathrm{x} \in \mathrm{S}}\{t \in G: F(x, t)=x\}=\cap_{\mathrm{u} \in \mathrm{G}} \cap_{\mathrm{k} \in \mathrm{K}}\left(-u+G_{\mathrm{k}}+u\right) .
$$

Proof. Let $\mathrm{s} \in\{\mathrm{t} \in \mathrm{G}: \mathrm{F}(\mathrm{x}, \mathrm{t})=\mathrm{x}\}$ for every $\mathrm{x} \in \mathrm{S}$. We have $\mathrm{G}_{\mathrm{k}}+\mathrm{u} \in \mathrm{G} / \mathrm{G}_{\mathrm{k}}$ for every $\mathrm{u} \in \mathrm{G}, \mathrm{k} \in \mathrm{K}$. There exists $\mathrm{y} \in \mathrm{S}_{\mathrm{k}}$ such that $\mathrm{b}_{\mathrm{k}}(\mathrm{y})=\mathrm{G}_{\mathrm{k}}+\mathrm{u}$. Since $\mathrm{s} \in\{\mathrm{t} \in \mathrm{G}: \mathrm{F}(\mathrm{y}, \mathrm{t})=$ $\mathrm{y}\}, \mathrm{y}=\mathrm{F}(\mathrm{y}, \mathrm{s})=b_{k}^{-1}\left(\mathrm{~b}_{\mathrm{k}}(\mathrm{y})+\mathrm{s}\right)$. From here $\mathrm{G}_{\mathrm{k}}+\mathrm{u}=\mathrm{G}_{\mathrm{k}}+\mathrm{u}+\mathrm{s}$. This yields that $-\mathrm{u}+\mathrm{G}_{\mathrm{k}}+\mathrm{u}=\left[-\mathrm{u}+\mathrm{G}_{\mathrm{k}}+\mathrm{u}\right]+\mathrm{s}$, thus $\mathrm{s} \epsilon\left[-\mathrm{u}+\mathrm{G}_{\mathrm{k}}+\mathrm{u}\right]$ for every $\mathrm{u} \epsilon \mathrm{G}, \mathrm{k} \in \mathrm{K}$.

Let $\mathrm{s} \epsilon\left(-\mathrm{u}+\mathrm{G}_{\mathrm{k}}+\mathrm{u}\right)$ for every $\mathrm{u} \in \mathrm{G}, \mathrm{k} \in \mathrm{K}$ and $\mathrm{x} \in \mathrm{S}_{\mathrm{k}}$. Then $\mathrm{b}_{\mathrm{k}}(\mathrm{x})=\mathrm{G}_{\mathrm{k}}+\mathrm{a}(\mathrm{x})$ for some $\mathrm{a}(\mathrm{x}) \epsilon \mathrm{G}$. From here $\mathrm{b}_{\mathrm{k}}(\mathrm{x})+\mathrm{s}=\mathrm{a}(\mathrm{x})+\left[-\mathrm{a}(\mathrm{x})+\mathrm{G}_{\mathrm{k}}+\mathrm{a}(\mathrm{x})\right]+\mathrm{s}=\mathrm{b}_{\mathrm{k}}(\mathrm{x})$, thus $\mathrm{F}(\mathrm{x}, \mathrm{s})=b_{k}^{-1}(\mathrm{~b}(\mathrm{x})+\mathrm{s})=\mathrm{x}$.

Note that if $\cap_{\mathrm{u} \in \mathrm{G}} \cap_{\mathrm{k} \in \mathrm{K}}\left(-\mathrm{u}+\mathrm{G}_{\mathrm{k}}+\mathrm{u}\right)=\{0\}$, then $\mathrm{g}(\mathrm{t})=\mathrm{t}$ for $\mathrm{t} \epsilon \mathrm{G}$ is the only solution of (15).

If the group $\mathrm{G}$ is abelian, then the function $\mathrm{g}$ in Lemma 1 is a homomorphism if and only if the function $\mathrm{g}(\mathrm{t})-\mathrm{t}$ is a homomorphism. We have thus by Lemmas 1 and 2 the following theorem.

Theorem 5. Let $F$ be as in Lemma 2. Assume that the group $G$ is abelian. The homomorphism $h: G \rightarrow G$ is a solution of $E q$. (15) if and only if $h(t)=h_{1}(t)+t$ for $t \in G$, where $h_{1}$ is an arbitrary homomorphism from $G$ to $\cap_{\mathrm{k} \in \mathrm{K}} G_{\mathrm{k}}$.

Remarks. 1/ If the group G is not abelian, then Theorem 5 is not true since the difference of two homomorphism may not be a homomorphism. E.g., for the smallest non-abelian group given in the table below and for $\mathrm{h}(\mathrm{t})=-\mathrm{a}+\mathrm{t}+\mathrm{a}$ the function $\mathrm{h}_{1}(\mathrm{t})=\mathrm{h}(\mathrm{t})-\mathrm{t}$ is not a homomorphism. Indeed, $\mathrm{h}_{1}(\mathrm{a}+\mathrm{b})=\mathrm{c} \neq$ $\mathrm{d}=\mathrm{h}_{1}(\mathrm{a})+\mathrm{h}_{1}(\mathrm{~b})$. 


\begin{tabular}{|c|c|c|c|c|c|c|}
\hline+ & 0 & a & b & c & d & e \\
\hline 0 & 0 & a & b & c & d & e \\
\hline a & a & o & c & b & e & d \\
\hline b & b & d & 0 & e & a & c \\
\hline c & c & e & a & d & 0 & b \\
\hline d & d & b & e & 0 & c & a \\
\hline e & e & c & d & a & b & o \\
\hline
\end{tabular}

The assumption that $\mathrm{G}$ is abelian in the above Theorem 5 can not be replaced by the assumption that $\mathrm{G}_{\mathrm{k}}$ are abelian in $\mathrm{F}$ for $\mathrm{k} \in \mathrm{K}$. We give an example below.

Let $\mathrm{S}=\{1,2\}$ and $\mathrm{K}=\{1\}$. Let $\mathrm{G}$ be a group as in the table above. Put $b_{1}(1)=\{0, c, d\}, b_{1}(2)=\{a, b, e\}$ and $F(x, t)=b_{1}^{-1}\left(b_{1}(x)+t\right)$ for $x \in S, t \in G$. Then $\mathrm{G}_{1}=\{0, \mathrm{c}, \mathrm{d}\}$ is an abelian group, the homomrphism $\mathrm{h}(\mathrm{t})=-\mathrm{a}+\mathrm{x}+\mathrm{a}$ is a solution of (15) and $\mathrm{h}(\mathrm{t})-\mathrm{t}$ is not a homomorphism.

The tables of these functions $F(x, t), h(t)$ and $F(x, h(t))$ are shown below.

\begin{tabular}{|c|c|c|c|c|c|c|}
\hline$F(x, t)$ & 0 & $a$ & $b$ & $c$ & $d$ & $e$ \\
\hline 1 & 1 & 2 & 2 & 1 & 1 & 2 \\
\hline 2 & 2 & 1 & 1 & 2 & 2 & 1 \\
\hline
\end{tabular}

\begin{tabular}{|c|c|c|c|c|c|c|}
\hline$t$ & 0 & a & b & c & $d$ & e \\
\hline$h(t)$ & 0 & a & e & d & c & b \\
\hline$F(x, h(t))$ & 0 & a & b & c & d & e \\
\hline 1 & 1 & 2 & 2 & 1 & 1 & 2 \\
\hline 2 & 2 & 1 & 1 & 2 & 2 & 1 \\
\hline
\end{tabular}

2/ If a homomorphism $\mathrm{h}: \mathrm{G} \rightarrow \mathrm{G}$ is a solution of (15), then

$$
h(t)=h(s) \Rightarrow F(x, t)=F(x, s) \text { for } x \in S, t, s \in G \text {. }
$$

Examples. 12. An equation of the form (15) can have a solution which is not the identity function. In fact, let $S=G=\mathbb{R}$ and let $\mathfrak{b}_{1}, \mathfrak{b}_{2}$ be different elements of the Hamel base $H$ of $\mathbb{R}$ over $\mathbb{Q}$. Let $a, h: \mathbb{R} \rightarrow \mathbb{R}$ be additive functions such that $\mathrm{a}\left(\mathfrak{b}_{1}\right)=\mathrm{a}\left(\mathfrak{b}_{2}\right)=\mathfrak{b}_{1}, \mathrm{~h}\left(\mathfrak{b}_{1}\right)=\mathfrak{b}_{2}, \mathrm{~h}\left(\mathfrak{b}_{2}\right)=\mathfrak{b}_{1}, \mathrm{a}(\mathrm{t})=$ $\mathrm{h}(\mathrm{t})=0$ for $\mathrm{t} \epsilon \mathrm{H} \backslash\left\{\mathfrak{b}_{1}, \mathfrak{b}_{2}\right\}$. We have for $\mathrm{t}=\mathrm{q}_{1} \mathfrak{b}_{1}+\mathrm{q}_{2} \mathfrak{b}_{2}+\mathrm{q}_{3} \mathfrak{b}_{3}+\cdots+\mathrm{q}_{\mathrm{n}} \mathfrak{b}_{\mathrm{n}}$, where $q_{i} \in \mathbb{Q}, \mathfrak{b}_{i} \in H$ for $\mathrm{i}=1, \ldots, \mathrm{n}$, that

$$
\begin{aligned}
\mathrm{a}(\mathrm{h}(\mathrm{t})) & =\mathrm{a}\left(\mathrm{q}_{1} \mathrm{~h}\left(\mathfrak{b}_{1}\right)+\mathrm{q}_{2} \mathrm{~h}\left(\mathfrak{b}_{2}\right)\right)=\mathrm{a}\left(\mathrm{q}_{1} \mathfrak{b}_{2}+\mathrm{q}_{2} \mathfrak{b}_{1}\right)=\mathrm{q}_{1} \mathrm{a}\left(\mathfrak{b}_{2}\right)+\mathrm{q}_{2} \mathrm{a}\left(\mathfrak{b}_{1}\right)=\left(\mathrm{q}_{1}+\mathrm{q}_{2}\right) \mathfrak{b}_{1} \\
& =\mathrm{q}_{1} \mathrm{a}\left(\mathfrak{b}_{1}\right)+\mathrm{q}_{2} \mathrm{a}\left(\mathfrak{b}_{2}\right)=\mathrm{a}\left(\mathrm{q}_{1} \mathfrak{b}_{1}+\mathrm{q}_{2} \mathfrak{b}_{2}+\mathrm{q}_{3} \mathfrak{b}_{3}+\cdots+\mathrm{q}_{\mathrm{n}} \mathfrak{b}_{\mathrm{n}}\right)=\mathrm{a}(\mathrm{t}) .
\end{aligned}
$$


From here for $\mathrm{F}(\mathrm{x}, \mathrm{t})=\mathrm{x}+\mathrm{a}(\mathrm{t})$ we obtain $\mathrm{F}(\mathrm{x}, \mathrm{h}(\mathrm{t}))=\mathrm{x}+\mathrm{a}(\mathrm{h}(\mathrm{t}))=$ $\mathrm{x}+\mathrm{a}(\mathrm{t})=\mathrm{F}(\mathrm{x}, \mathrm{t})$. The function $\mathrm{h}_{1}$ of Theorem 6 is here of the form $\mathrm{h}_{1}(\mathrm{t})=\left(\mathrm{q}_{2}-\mathrm{q}_{1}\right) \mathfrak{b}_{1}+\left(\mathrm{q}_{1}-\mathrm{q}_{2}\right) \mathfrak{b}_{2}-\mathrm{q}_{3} \mathfrak{b}_{3}-\cdots-\mathrm{q}_{\mathrm{n}} \mathfrak{b}_{\mathrm{n}}$ for $\mathrm{t}$ as above.

13. If $\mathrm{F}_{\mathrm{i}}(\mathrm{x}, \mathrm{t})=\mathrm{x}$ for $(\mathrm{x}, \mathrm{t}) \in\left(\mathrm{S}_{\mathrm{i}}, \mathrm{G}_{\mathrm{i}}\right)$ and $\mathrm{i}=1,2$ and $\mathrm{f}: \mathrm{S}_{1} \rightarrow \mathrm{S}_{2}$ is an arbitrary function, then the arbitrary function $h: G_{1} \rightarrow G_{2}$ is a solution of (1).

14. If functions $\mathrm{F}_{1}, \mathrm{~F}_{2}$, f are as in Example 1, then Eq. (1) has the form

$$
\varepsilon \exp (\mathrm{a}+\mathrm{tn} \mathrm{x}+\mathrm{t})=\varepsilon \exp (\mathrm{a}+\mathrm{tnx}+\mathrm{h}(\mathrm{t})) .
$$

Thus if $\varepsilon \neq 0$, then $\mathrm{h}(\mathrm{t})=\mathrm{t}$ is the only solution of (1) and if $\varepsilon=0$, then every function $h: \mathbb{R} \rightarrow \mathbb{R}$ is a solution of this equation.

15. The homomorphism $\mathrm{h}(\mathrm{t})=\mathrm{t}$ is not a solution of (1) in Example 2 .

16. If $\mathrm{S}_{1}=\mathrm{S}_{2}=\mathrm{G}_{1}=\mathrm{G}_{2}=\mathbb{Z}, \mathrm{F}_{1}(\mathrm{x}, \mathrm{t})=\mathrm{F}_{2}(\mathrm{x}, \mathrm{t})=\mathrm{x}+\mathrm{t}$ and $\mathrm{f}(\mathrm{x})=2 \mathrm{x}$, then Eq. (1) has the form $2(x+t)=2 x+h(t)$. From here $h(t)=2 t$ is the only homomorphism which is a solution of (1).

17. Let $\mathrm{G}_{1}$ be a semigroupe, let $\mathrm{G}_{2}$ be a semigroupe with the left cancellation property and let $\mathrm{S}_{1}=\mathrm{G}_{1}, \mathrm{~S}_{2}=\mathrm{G}_{2}, \mathrm{~F}_{1}(\mathrm{x}, \mathrm{t})=\mathrm{x}+\mathrm{t}: \mathrm{G}_{1} \times \mathrm{G}_{1} \rightarrow \mathrm{G}_{1}$, $\mathrm{F}_{2}(\mathrm{u}, \mathrm{v})=\mathrm{u}+\mathrm{v}: \mathrm{G}_{2} \times \mathrm{G}_{2} \rightarrow \mathrm{G}_{2}$. If a function $\mathrm{f}: \mathrm{G}_{1} \rightarrow \mathrm{G}_{2}$ is a homomorphism, then $\mathrm{h}=\mathrm{f}$ is the only solution of Eq. (1). In fact, Eq. (1) has the form $f(x+t)=f(x)+h(t)$.

\section{Conditional equation (11)}

The conditional equation (11) is said to be the equation associated with the geometric concomitant equation (1). If functions $\mathrm{f}, \mathrm{F}_{1}, \mathrm{~F}_{2}$, h satisfy (1), then $\mathrm{f}, \mathrm{F}_{1}, \mathrm{~h}$ are evidently solutions of (11) and if $\mathrm{f}, \mathrm{F}_{1}, \mathrm{~h}$ satisfy (11), then there exists $\mathrm{F}_{2}: \mathrm{S}_{2} \times \mathrm{h}\left(\mathrm{G}_{1}\right)$ such that $\mathrm{f}, \mathrm{F}_{1}, \mathrm{~h}, \mathrm{~F}_{2}$ are solutions of (1) by Theorem 3 . A solution of the translation equation $\mathrm{F}_{2}$ with this property and defined on $\mathrm{S}_{2} \times \mathrm{G}_{2}$ may not exist (see Example 8 ). We consider the conditional equation (11) (without the index , 1 " in $\mathrm{F}_{1}$ ) in the cases if

(i) the homomorphism $\mathrm{h}$ is injective and $\mathrm{G}_{1}=\mathrm{G}_{2}$

or

(ii) the function $\mathrm{f}$ is injective and $\mathrm{S}_{1}=\mathrm{S}_{2}$.

In case (i) the functions f,h,F are solutions of (11) if and only if

$$
f(x)=f(y) \Rightarrow f[F(x, t)]=f[F(y, t)] \text { for } x, y, t \in G .
$$

In case (ii) the functions f,h $\mathrm{F}$ are solutions of (11) if and only if

$$
\mathrm{h}(\mathrm{t})=\mathrm{h}(\mathrm{s}) \Rightarrow \mathrm{F}(\mathrm{x}, \mathrm{t})=\mathrm{F}(\mathrm{x}, \mathrm{s}) \text { for } \mathrm{x} \in \mathrm{S}, \mathrm{t}, \mathrm{s} \in \mathrm{G} .
$$

Theorem 6. Let $G$ be a group. A function $f: S \rightarrow S$ is a solution of the conditional equation (17), where $F(x, t)=b^{-1}(b(x)+t)$ and $b: S \rightarrow G$ is a bijection, if and only if $f(x)=b^{-1} \Phi([b(x)])$ for $x \in S$, where $[x] \epsilon G / G^{*}$ for some subgroup $G^{*}$ of $G$ and $\Phi$ is an injection from $G / G^{*}$ to $G$. 
Proof. If $\mathrm{b}^{-1} \Phi([\mathrm{b}(\mathrm{x})])=\mathrm{b}^{-1} \Phi([\mathrm{b}(\mathrm{y})])$, then $[\mathrm{b}(\mathrm{x})]=[\mathrm{b}(\mathrm{y})]$. From here $(\mathrm{b}(\mathrm{x})+$ $\mathrm{t})-(\mathrm{b}(\mathrm{y})+\mathrm{t})=\mathrm{b}(\mathrm{x})-\mathrm{b}(\mathrm{y}) \epsilon \mathrm{G}^{*}$ for every $\mathrm{t} \epsilon \mathrm{G}$. This yields that $[\mathrm{b}(\mathrm{x})+\mathrm{t}]=$ $[\mathrm{b}(\mathrm{y})+\mathrm{t}]$. This implies that

$\mathrm{b}^{-1} \Phi([\mathrm{b}(\mathrm{F}(\mathrm{x}, \mathrm{t}))])=\mathrm{b}^{-1} \Phi([\mathrm{b}(\mathrm{x})+\mathrm{t}])=\mathrm{b}^{-1} \Phi([\mathrm{b}(\mathrm{y})+\mathrm{t}])=\mathrm{b}^{-1} \Phi([\mathrm{b}(\mathrm{F}(\mathrm{y}, \mathrm{t}))])$.

Analogously, if $\mathrm{f}$ is a solution of $(15)$, then $\varphi(\mathrm{u})=\mathrm{bfb}^{-1}(\mathrm{u})$ for $\mathrm{u} \in \mathrm{G}$ is a solution of the implication

$$
\varphi(\mathrm{u})=\varphi(\mathrm{v}) \Rightarrow \varphi(\mathrm{u}+\mathrm{t})=\varphi(\mathrm{v}+\mathrm{t}) .
$$

We define a relation $\mathrm{R}$ on $\mathrm{G}$ : $\mathrm{uRv} \Leftrightarrow[\varphi(\mathrm{u})=\varphi(\mathrm{v})]$. It is an equivalence relation and $u R v$ implies $(u+t) R(v+t)$. From here the family of equivalence classes of $R$ is the same as the family $G / G^{*}$ for some subgroup $G^{*}$ [3]. Let $S$ be a selector of this family. Put $\Phi([u])=\varphi\left(u_{0}\right)$, where $u_{0} \in S \cap[u]$. Since $u_{0} \in[u]$, $[\mathrm{u}]=\left[\mathrm{u}_{0}\right]$. For $\mathrm{u} \in[\mathrm{u}]=\left[\mathrm{u}_{0}\right]$ we have $\varphi(\mathrm{u})=\varphi\left(\mathrm{u}_{0}\right)$, thus $\varphi(\mathrm{u})=\Phi([\mathrm{u}])$. From here $f(x)=b^{-1} \Phi([b(x)])$.

Example. 18. Consider the conditional equation (16) where $\mathrm{F}$ is a function as in (2). The function $\mathrm{f}(\mathrm{x})=\Phi(\mathrm{k})$ for $\mathrm{x}_{\mathrm{C}} \mathrm{S}_{1 \mathrm{k}}$, where $\Phi$ is a function from $K_{1}$ to $S_{1}$, is a solution of this condition. In fact, if $\mathrm{f}(\mathrm{x})=\mathrm{f}(\mathrm{y}), \mathrm{f}(\mathrm{x})=\Phi(\mathrm{k})$ for $\mathrm{x}_{\epsilon} \mathrm{S}_{1 \mathrm{k}}$ and $\mathrm{f}(\mathrm{y})=\Phi(\mathrm{l})$ for $\mathrm{y} \in \mathrm{S}_{1 \mathrm{l}}$, then $\Phi(\mathrm{k})=\Phi(\mathrm{l})$. Since $\mathrm{F}_{1}(\mathrm{x}, \mathrm{t}) \in \mathrm{S}_{1 \mathrm{k}}$ for $t \in \mathrm{G}_{1}, \mathrm{f}\left[\mathrm{F}_{1}(\mathrm{x}, \mathrm{t})\right]=\Phi(\mathrm{k})$. Analogously $\mathrm{f}\left[\mathrm{F}_{1}(\mathrm{y}, \mathrm{t})\right]=\Phi(\mathrm{l})$. From here $\mathrm{f}\left[\mathrm{F}_{1}(\mathrm{x}, \mathrm{t})\right]=\mathrm{f}\left[\mathrm{F}_{1}(\mathrm{y}, \mathrm{t})\right]$.

Example. 19. Let $\mathrm{F}(\mathrm{x}, \mathrm{t})=\mathrm{x}+\mathrm{t}$ be a function from $\mathbb{R} \times \mathbb{R}$ to $\mathbb{R}$, let $\mathrm{G}$ be the additive group of real numbers. The function $\Phi([\mathrm{x}])=\mathrm{M}(\mathrm{x})$ for $[\mathrm{x}] \in \mathbb{R} / \mathbb{Z}$, where $M(x)$ is the mantissa of $x \in \mathbb{R}$, is an injection from $\mathbb{R} / \mathbb{Z}$ to $\mathbb{R}$. From here $\mathrm{M}(\mathrm{x})$ is a solution of (15) and it is not a solution of Eq. (7).

Proposition. Let $G$ be a group and let $F: S \times G \rightarrow S$ be a solution of the translation equation such that $F(x, 0)=x$ for $x \in S$. A homomorphism $h: G \rightarrow G$ is a solution of the conditional equation (18) if and only if

$$
\operatorname{Kern}(h) \subset \cap_{\mathrm{x} \in \mathrm{S}}\{s \in G: F(x, s)=x\} .
$$

Proof. If $\mathrm{h}$ is a solution of (18) and $\mathrm{t} \in \operatorname{Kern}(\mathrm{h})$, then $\mathrm{h}(\mathrm{t})=0=\mathrm{h}(0)$, thus $\mathrm{F}(\mathrm{x}, \mathrm{t})=\mathrm{F}(\mathrm{x}, 0)=\mathrm{x}$ for every $\mathrm{x} \in \mathrm{S}$. Fom here $t \in \cap_{\mathrm{x} \in \mathrm{S}}\{\mathrm{s} \in \mathrm{G}: \mathrm{F}(\mathrm{x}, \mathrm{s})=\mathrm{x}\}$.

Assume that (19) is true. If $\mathrm{h}(\mathrm{t})=\mathrm{h}(\mathrm{s})$, then $\mathrm{h}(\mathrm{t}-\mathrm{s})=0$, thus $\mathrm{t}-\mathrm{s} \in \operatorname{Kern}(\mathrm{h})$. This yields that $\mathrm{F}(\mathrm{x}, \mathrm{t}-\mathrm{s})=\mathrm{x}$ for $\mathrm{x} \in \mathrm{S}$. From here $\mathrm{F}(\mathrm{x}, \mathrm{t})=\mathrm{F}(\mathrm{F}(\mathrm{x}, \mathrm{t}-\mathrm{s}), \mathrm{s})=$ $\mathrm{F}(\mathrm{x}, \mathrm{s})$.

Example. 20. Let $\mathrm{S}, \mathrm{G}, \mathrm{H}$ be as in Example 10. Let $\mathrm{F}(\mathrm{x}+\mathrm{t})=\mathrm{x}+\mathrm{t}$. For the homomorphism

$$
\mathrm{h}\left(\mathrm{q}_{1} \mathfrak{b}_{1}+\mathrm{q}_{2} \mathfrak{b}_{2}+\mathrm{q}_{3} \mathfrak{b}_{3}+\cdots+\mathrm{q}_{\mathrm{n}} \mathfrak{b}_{\mathrm{n}}\right)=\mathrm{q}_{2} \mathfrak{b}_{1}+\mathrm{q}_{1} \mathfrak{b}_{2}+\mathrm{q}_{3} \mathfrak{b}_{3}+\cdots+\mathrm{q}_{\mathrm{n}} \mathfrak{b}_{\mathrm{n}}
$$

we have $\operatorname{Kern}(\mathrm{h})=\{0\}$, $\mathrm{h}$ satisfies (19). This implies that $\mathrm{h}$ is a solution of (18). This function $h$ is evidently not a solution of (17). 
Example. 21. Injection from $\mathbb{R}$ to $\mathbb{R}$ and constant function are the only solutions of (17) for the geometric object $\mathrm{x}=\mathrm{v}_{2} / \mathrm{v}_{1}$, where $\mathrm{v}_{1}, \mathrm{v}_{2}$ are the coordinates of the 2-dimensional contravariant vector. Indeed, this object has the transformation law of the form $\frac{A_{1}^{1}+A_{2}^{1} x}{A_{1}^{2}+A_{2}^{2} x}[1]$. Thus (17) is of the form

$$
\mathrm{f}(\mathrm{x})=\mathrm{f}(\mathrm{y}) \Rightarrow \mathrm{f}\left(\frac{A_{1}^{1}+A_{2}^{1} x}{A_{1}^{2}+A_{2}^{2} x}\right)=\mathrm{f}\left(\frac{A_{1}^{1}+A_{2}^{1} y}{A_{1}^{2}+A_{2}^{2} y}\right) .
$$

For $A_{2}^{1}=A_{1}^{2}=1$ and $A_{2}^{2}=0$ we have

$$
\mathrm{f}(\mathrm{x})=\mathrm{f}(\mathrm{y}) \Rightarrow \mathrm{f}\left(A_{1}^{1}+x\right)=\mathrm{f}\left(A_{1}^{1}+y\right)
$$

for every x, y, $A_{1}^{1} \in \mathbb{R}$. From here the family $F$ of the levels of $\mathrm{f}$ is invariant under arbitrary translations. This yields that this family $F=\mathbb{R} / \mathbb{R}^{*}$ for a subgroupe $\mathbb{R}^{*}$ of $\mathbb{R}$. Assume that $\{0\} \neq \mathbb{R}^{*} \neq \mathbb{R}$. This implies that there exist $\mathrm{x}_{1}, \mathrm{x}_{2}$ such that $\mathrm{x}_{1} \neq 0$ and $\mathrm{f}(0)=\mathrm{f}\left(\mathrm{x}_{1}\right) \neq \mathrm{f}\left(\mathrm{x}_{2}\right)$. We have by $(20)$ that $\mathrm{f}(\mathrm{x})=\mathrm{f}(\mathrm{y}) \Rightarrow \mathrm{f}(\mathrm{ax})=\mathrm{f}($ ay $)$ for every $\mathrm{x}, \mathrm{y}, \mathrm{a} \in \mathbb{R}$. From here

$$
\mathrm{f}(0)=\mathrm{f}\left(\frac{x_{2}}{x_{1}} \cdot 0\right)=\mathrm{f}\left(\frac{x_{2}}{x_{1}} \mathrm{x}_{1}\right)=\mathrm{f}\left(\mathrm{x}_{2}\right),
$$

thus a contradiction. If $\mathbb{R}^{*}=\{0\}$, then $\mathrm{f}$ is an injection. If $\mathbb{R}^{*}=\mathbb{R}$, then $\mathrm{f}$ is a constant function.

Open Access. This article is licensed under a Creative Commons Attribution 4.0 International License, which permits use, sharing, adaptation, distribution and reproduction in any medium or format, as long as you give appropriate credit to the original author(s) and the source, provide a link to the Creative Commons licence, and indicate if changes were made. The images or other third party material in this article are included in the article's Creative Commons licence, unless indicated otherwise in a credit line to the material. If material is not included in the article's Creative Commons licence and your intended use is not permitted by statutory regulation or exceeds the permitted use, you will need to obtain permission directly from the copyright holder. To view a copy of this licence, visit http:// creativecommons.org/licenses/by/4.0/.

Publisher's Note Springer Nature remains neutral with regard to jurisdictional claims in published maps and institutional affiliations.

\section{References}

[1] Aczél, J., Gołąb, S.: Funktionalgleichungen der Theorie der geometrischen Objekte, Państwowe Wydawnictwo Naukowe, Warszawa, Monografie Matematyczne 39, (1960)

[2] Baron, K., Chojnacki, W., Jaczyk, W.: Continuity of solutions of the translation equation. Aequ. Math. 74, 314-317 (2007)

[3] Bourbaki, N.: Éléments de mathématique. Livre II, Algèbre, Chapitre I, Structures algébriques, Paris (1951)

[4] Gołąb, S.: Sur quelques points concernant la notion du comitant. Ann. Soc. Pol. Math. 17, 17-192 (1938)

[5] Łojasiewicz, S.: Sur le probléme d'itération. Colloq. Math. 3, 176-177 (1955) 
[6] Moszner, Z.: Sur le prolongement des objets géométriques transitifs. Tensor N.S. 26, 239-242 (1972)

[7] Moszner, Z.: Structure de l'automate plein, réduit et inversible. Aequ. Math. 9(1), 46-59 (1973)

[8] Moszner, Z., Pilecka, B.: Sur le prolongement des objets géométriques non-transitifs. Tensor N.S. 28, 63-66 (1974)

[9] Moszner, Z.: Sur l'équation du comitant. Tensor N.S. 51, 205-208 (1992)

[10] Moszner, Z.: Miscelanea about the stability of functional equations. In: Ulam Type Stability, pp. 231-271, Springer, Berlin (2019)

[11] Starke, P.H.: Abstract Automata. Nort-Holland Publishing Company, AmsterdamLondon, Amercan Elsevier Publishing Company, New York (1972)

Zenon Moszner

Institute of Mathematics

Pedagogical University

Podchorążych 2

30-084 Kraków

Poland

e-mail: zenon.moszner@e.up.krakow.pl

Received: March 16, 2019

Revised: January 4, 2020 